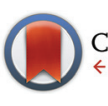

CrossMark \&lick for updates

Cite this: Dalton Trans., 2015, 44 8640

Received 20th January 2015, Accepted 25th March 2015

DOI: $10.1039 / \mathrm{c} 5 \mathrm{dt} 00287 \mathrm{~g}$

www.rsc.org/dalton

\title{
Polypyridyl Ru(II)-derivatized polypropylacrylate polymer with a terminal water oxidation catalyst. Application of reversible addition-fragmentation chain transfer polymerization $\dagger$
}

\author{
Zhen Fang, ${ }^{a}$ Akitaka Ito, ${ }^{\text {a,b }}$ Hanlin Luo, ${ }^{a}$ Dennis L. Ashford, ${ }^{a}$ Javier J. Concepcion, ${ }^{a}$ \\ Leila Alibabaei ${ }^{a}$ and Thomas J. Meyer ${ }^{* a}$
}

\begin{abstract}
A Ru(II) polypyridyl-derivatized polypropylacrylate end-capped with a water-oxidation-catalyst (WOC) has been synthesized by using reversible addition-fragmentation chain transfer polymerization (RAFT) followed by click reaction and end-group functionalization. In cyclic voltammograms in propylene carbonate, chromophore oxidation occurs at $1.27 \mathrm{~V}$ vs. NHE and the Rull/III wave for the catalyst at $0.84 \mathrm{~V}$ vs. NHE. Upon excitation of the Ru(II) chromophore, excited-state energy migration occurs by site-to-site,

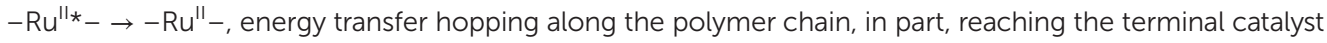
site where $-\mathrm{Ru}^{\mathrm{Il}{ }_{-} \rightarrow-} \rightarrow-\mathrm{Ru}^{\mathrm{II}}-\mathrm{OH}_{2}{ }^{2+}$ energy transfer is favored by $\Delta G_{\mathrm{en}}=-2100 \mathrm{~cm}^{-1}$. Added $\mathrm{MV}^{2+}$ as an

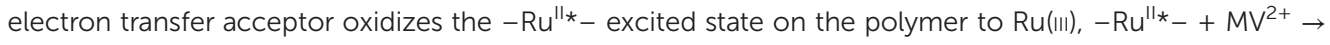
$-\mathrm{Ru}^{\prime \prime \prime}-+\mathrm{MV}^{+}$, and ultimately, the catalyst, by site-to-site electron transfer hopping and oxidation, $-\mathrm{Ru}^{\prime \prime \prime}-\stackrel{e^{-}}{\longleftarrow}-\mathrm{Ru}^{\prime \prime}-\mathrm{OH}_{2}{ }^{2+}$. Oxidation is followed by relatively slow, diffusional back electron transfer from $\mathrm{MV}^{++}$to $\mathrm{Ru}(\mathrm{III})$ sites on the polymer chain. The mixed chromophore-catalyst polymer is a water oxidation catalyst with potential for enhanced light harvesting and water oxidation.
\end{abstract}

\section{Introduction}

Dye-sensitized photoelectrosynthesis cells (DSPEC) provide a straightforward design for solar conversion to fuels through water splitting to hydrogen and oxygen, and/or $\mathrm{CO}_{2}$ reduction to reduced carbon fuels. ${ }^{1}$ Water oxidation catalysis is a key element in such designs with stepwise oxidative activation occurring on the surfaces of high band gap semiconductor oxides. $^{2}$ Given the wide band gap of useful semiconductors such as $\mathrm{TiO}_{2}$, with a band gap of $3.2 \mathrm{eV}$, an integrated chromophore sensitizer is required to absorb light, undergo excitedstate injection, and transfer oxidizing equivalents to an associated catalyst for water oxidation. Considerable progress has been made in designing and investigating appropriate chromophore-catalyst assemblies. ${ }^{3}$

One successful strategy is surface binding of assemblies ${ }^{4}$ to the surface of $\mathrm{TiO}_{2} .{ }^{5}$ Excitation of the chromophore and elec-

\footnotetext{
${ }^{a}$ Department of Chemistry, University of North Carolina at Chapel Hill, CB3290, Chapel Hill, North Carolina 27599, USA. E-mail: tjmeyer@unc.edu

${ }^{b}$ Department of Chemistry, Graduate School of Science, Osaka City University, 3-3-138, Sugimoto, Sumiyoshi-ku, Osaka 558-8585, Japan

$\dagger$ Electronic supplementary information (ESI) available: Synthesis and characterization details, absorption and emission spectra, GPC, and electrochemistry. See DOI: $10.1039 / \mathrm{c} 5 \mathrm{dt} 00287 \mathrm{~g}$
}

tron injection by the resulting chromophore excited state into the $\mathrm{TiO}_{2}$ conduction band is followed by oxidative activation of the catalyst by intra-assembly electron transfer. In a recent example, use of a conjugated bridging ligand resulted in trapping of the excited-state electrons at the lowest-lying metal-toligand charge transfer (MLCT) state localized on the ligand, greatly decreasing the electron injection efficiency. ${ }^{6}$ In a modification, chromophore-catalyst assemblies with non-conjugated bridging ligands were used to significantly increase injection, ${ }^{7}$ providing a feasible assembly design strategy for DSPEC applications.

Another strategy is use of multiple chromophores in the chromophore-catalyst assembly as a way of enhancing the effective solar insolation rate which in ambient sunlight is $1-2 \mathrm{~s}^{-1} \cdot{ }^{8} \mathrm{Ru}(\mathrm{II})$ polypyridyl complexes have been incorporated into polymer scaffolds and utilized with the scaffolds used as light-harvesting antenna with high optical cross sections, ${ }^{9}$ with rapid, efficient charge/exciton transport between the adjacent ruthenium pendant units. $^{10}$ In this strategy, excitation of a single chromophore in the polymer chain, $-\mathrm{Ru}^{\mathrm{II}}-\stackrel{h \nu}{\longrightarrow}-\mathrm{Ru}^{\mathrm{II} *}-$, is followed by energy migration between

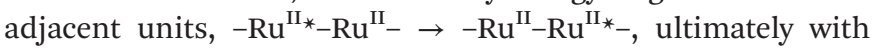
electron injection into the semiconductor, $\left(\mathrm{TiO}_{2}-\mathrm{Ru}^{\mathrm{II}_{*}} \rightarrow\right.$ $\left.\mathrm{TiO}_{2}\left(\mathrm{e}^{-}\right)-\mathrm{Ru}^{\mathrm{III}}-\right)$. Following injection, electron-transfer migration along the polymer strand occurs with oxidation 

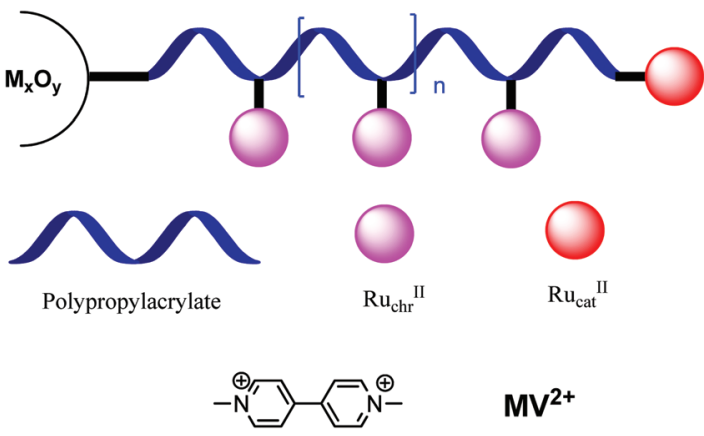

$\mathrm{MV}^{2+}$

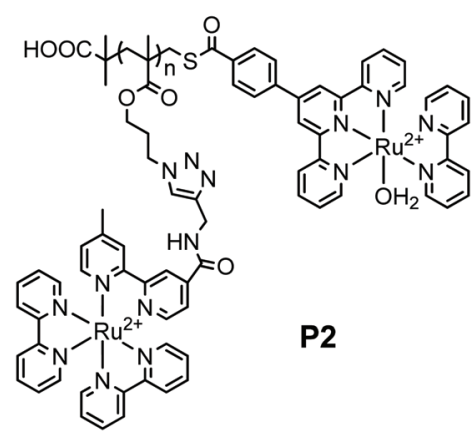

Chart 1 Polymer assembly structure.

of the catalyst, $-\mathrm{Ru}^{\mathrm{III}}-\mathrm{Ru}_{\text {cat }}^{\mathrm{II}} \rightarrow-\mathrm{Ru}^{\mathrm{II}}-\mathrm{Ru}_{\text {cat }}{ }^{\mathrm{III}}$, beginning the $4 \mathrm{e}^{-} / 4 \mathrm{H}^{+}$sequence for water oxidation.

We report here the synthesis of a poly(propylmethacrylate) derivative (P2, Chart 1) end-capped with the catalyst derivative, $\left[\left[4^{\prime} \text {-phenyl-2,2':6',2"-terpyridine }\right] \mathrm{Ru}(\mathrm{bpy})\left(\mathrm{H}_{2} \mathrm{O}\right)\right]^{2+}$ (bpy $=2,2^{\prime}$ bipyridine), by reversible addition-fragmentation chain transfer (RAFT) polymerization followed by a click reaction and end group functionalization. The RAFT polymerization features a dual end group-functionality in a one-pot synthesis and a sidefunctionality for adding $\mathrm{Ru}(\mathrm{II})$ polypyridyl chromophores by click coupling.

Several advantages are featured in this molecular design. The introduction of multiple $\mathrm{Ru}(\mathrm{II})$ chromophores enhances the light harvesting ability of the assembly relative to a single chromophore. Multi-site light absorption coupled with rapid intra-strand energy migration results in an increase in the effective rate of solar insolation. In the molecular design developed here, a channel exists for electron transfer hopping to and from the terminal catalyst through the $\mathrm{Ru}(\mathrm{II})$ sites on the polymer. Given the saturated spacers between sites on the polymer strands, inter-site electron transfer is presumably dominated by outer-sphere contact and orbital overlap. Because the catalyst site is at a terminus, it is held at a long distance from the oxide surface creating a spatial barrier to back electron transfer from the metal oxide surface to the catalyst. ${ }^{11}$

With these advantages in mind, we report here the synthesis and initial photophysical and electrochemical properties of a first example of a catalyst-terminated, polymeric $\mathrm{Ru}(\mathrm{II})$ polypyridyl assembly.

\section{Results and discussion}

Scheme 1 illustrates the synthetic route to the catalyst terminated, poly-chromophoric polymer, $\mathbf{P 2}$, with details provided in ESI. $\uparrow$ 3-Chloropropyl methacrylate (1) was synthesized by condensation of methacryloyl chloride with 3-chloropropan-1ol in the presence of triethylamine as the catalyst. Bulk polymerization of the acrylate yielded the polymer precursor PCPM in the presence of AIBN as the catalyst and 2-(dodecyl- thiocarbonothioylthio)-2-methylpropanoic acid (DDMAT, prepared by using a literature method ${ }^{12}$ ) as the RAFT agent. The chloride group in PCPM was substituted with azide upon treatment with $\mathrm{NaN}_{3}$, monitored by loss of a resonance at $3.65 \mathrm{ppm}$ and appearance of a new resonance at $3.42 \mathrm{ppm}$ in ${ }^{1}$ H-NMR spectra, Fig. S1 in the ESI. $\dagger$ The conversion yield was close to $96 \%$ calculated from the proton resonance integration. The trithiolester group disappeared after $\mathrm{NaN}_{3}$ treatment with a white solid appearing due to the loss of trithiolester group introduced by DDMAT. This is consistent with the absence of a $-\mathrm{C}_{12} \mathrm{H}_{25}$ proton resonance $(\sim 1.25 \mathrm{ppm})$ in the trithiolester group in the PNPM ${ }^{1} \mathrm{H}_{-}$NMR spectrum. The removal of trithiolester under basic condition has been reported in previous research. ${ }^{9}$ GPC analysis shows that the number average molecular weight $\left(M_{\mathrm{n}}\right)$ of PCPM is $3530 \mathrm{~g} \mathrm{~mol}^{-1}$ (degree of polymerization: 20); while the $M_{\mathrm{n}}$ of PNPM is $3090 \mathrm{~g} \mathrm{~mol}^{-1}$. The decrease in $M_{\mathrm{n}}$ is in agreement with the cleavage of the trithiol group, while the polydispersity index (PDI) remains constant (PDI 1.3, see GPC curves in Fig. S2 in the ESI $\dagger$ ).

The precursor polymer $\mathbf{P 1}$ was obtained by grafting [(4-CCbpy)Ru(bpy $\left.)_{2}\right]^{2+}$ onto the PNPM side chains via a click reaction between the azidopropyl functionality and the alkyne unit of $\left[(4-\mathrm{CC}-\mathrm{bpy}) \mathrm{Ru}(\mathrm{bpy})_{2}\right]^{2+}$. The orange precipitate from ethanol yielded a metallopolymer with $\mathrm{PF}_{6}{ }^{-}$as the counter ion, which is soluble in acetone, acetonitrile and DMF. Counter-ion metathesis to chloride provides the basis for further purification by dialysis (cutoff $M_{\mathrm{n}} \sim 3500$ Dalton) to remove unreacted [(4-CCbpy) $\left.R u(b p y)_{2}\right]^{2+}$. In the infrared spectrum of $\mathbf{P 1}$ there is no azide stretch at $\sim 2100 \mathrm{~cm}^{-1}$ consistent with the click reaction being essentially quantitative (See Fig. S3 in the ESI †े). The ${ }^{1} \mathrm{H}_{-}$NMR spectrum of $\mathbf{P 1}$ was dominated by resonances of the bipyridine ligands in the aromatic region. P1 was functionalized by condensation between the $-\mathrm{SH}$ terminus and $\left[\left[4-\left(\left[2,2^{\prime}: 6^{\prime}, 2^{\prime \prime} \text {-terpyridin }\right]-4^{\prime} \text {-yl)benzoyl chloride }\right] \mathrm{Ru}(\mathrm{bpy})(\mathrm{Cl})\right]^{+}\right.$, which was synthesized based on a previously described method. ${ }^{13}$ Dialysis was conducted to remove excess $\left[\left[4-\left(\left[2,2^{\prime}: 6^{\prime}, 2^{\prime \prime} \text {-terpyridin]-4'-yl)benzoyl chloride }\right] \mathrm{Ru}(\mathrm{bpy})(\mathrm{Cl})\right]^{+}\right.\right.$, which was hydrolyzed to [[4-([2,2':6',2"-terpyridin]-4'-yl)benzoyl acid]$\mathrm{Ru}(\mathrm{bpy})(\mathrm{Cl})]^{+}$during work-up. Treatment with silver triflate (AgOTf) resulted in the end group Ru(II) catalyst unit coordinated with $\mathrm{OTf}^{-}$. Precipitation from saturated $\mathrm{LiClO}_{4}$ 


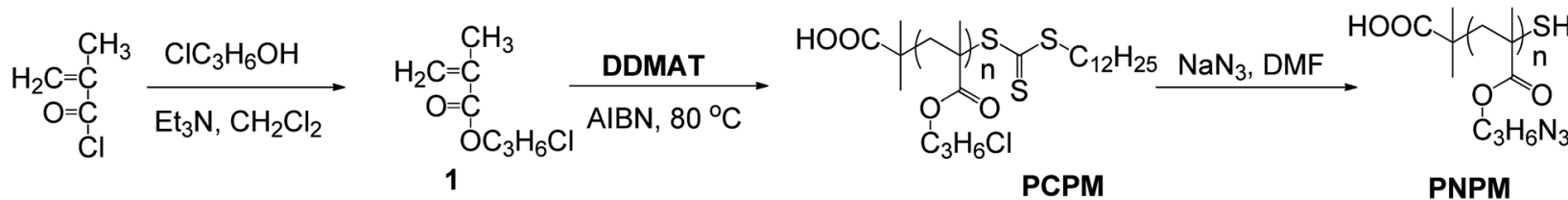

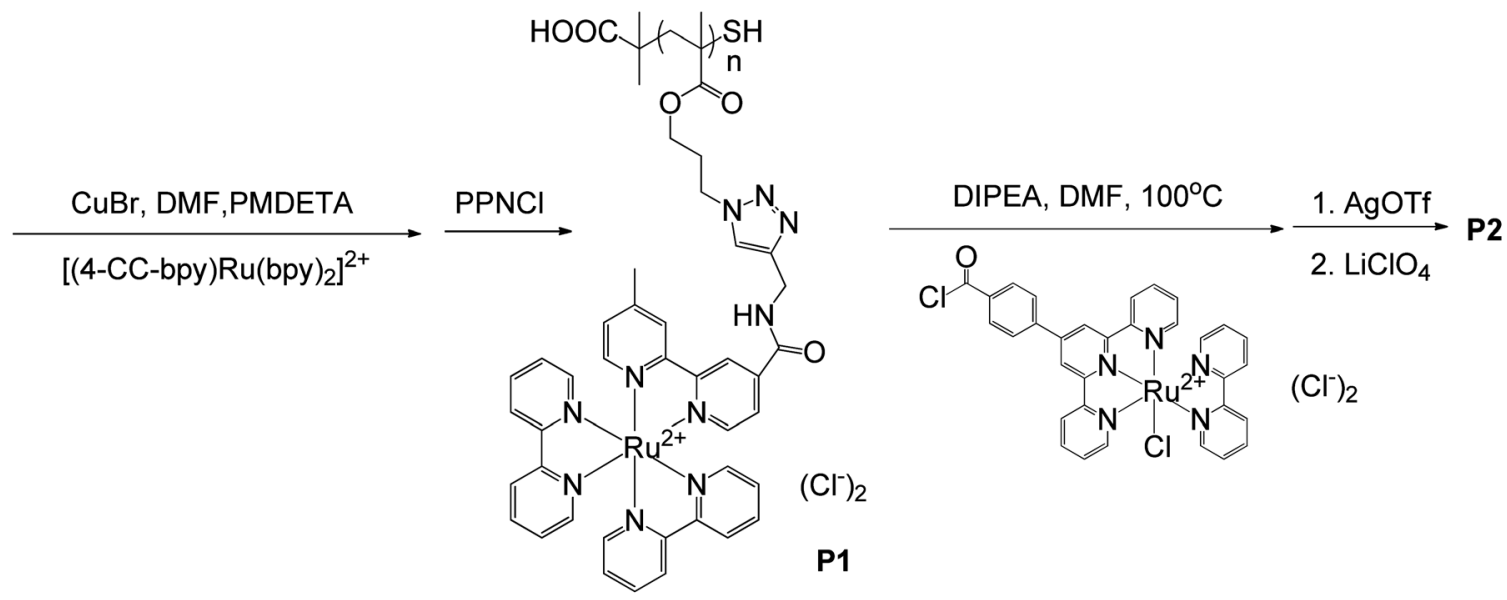

DDMAT: HOOC $\psi \mathrm{S}_{\mathrm{S}} \mathrm{S}^{\mathrm{S}} \mathrm{C}_{12} \mathrm{H}_{25}$

DIPEA:<smiles>CCN(C(C)C)C(C)C</smiles>

PMDETA:<smiles>CN(C)CCN(C)CCN(C)C</smiles>

$\left[(4-C C-b p y) R u(b p y)_{2}\right]^{2+}$ :
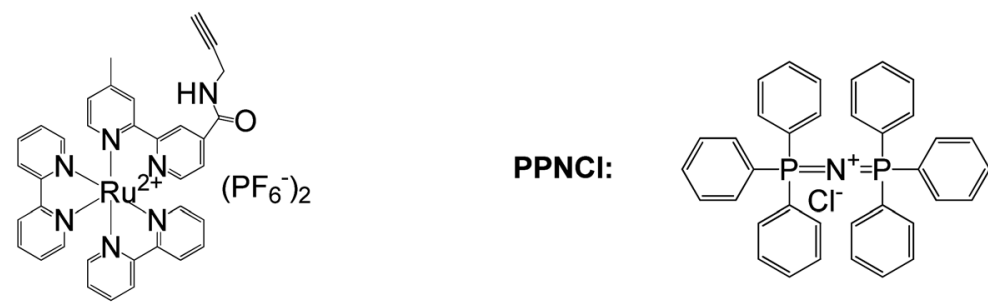

Scheme 1 Synthesis of P2.

produced a polymer with $\mathrm{Ru}_{\text {cat }}^{\mathrm{II}}$ in situ coordinated with $\mathrm{H}_{2} \mathrm{O}$ and counter ion metathesis from $\mathrm{OTf}^{-}$to $\mathrm{ClO}_{4}{ }^{-}$. The ${ }^{1} \mathrm{H} \_\mathrm{NMR}$ spectrum of $\mathbf{P} 2$ shows a pattern similar to $\mathbf{P 1}$, with the exception of a growing overlapped resonance at $\sim 7.2 \mathrm{ppm}$ and a weak resonance at $\sim 9.5 \mathrm{ppm}$ attributed to the protons at the terpyridine and bipyridine ligands of the catalyst.

\section{Electrochemistry}

The electrochemical properties of $\mathbf{P 1}$ and $\mathbf{P} 2$ were studied by cyclic voltammetry (CV) and differential pulse voltammetry (DPV) in both solution and on nano-ITO (tin-doped indium oxide) substrates. Fig. 1 shows anodic DPV scan for P1, P2, and a mixture of $\mathbf{P 1}$ with $\left[\left[4^{\prime}\right.\right.$-phenyl-2,2':6',2"-terpyridine]Ru(bpy) $\left.\left(\mathrm{H}_{2} \mathrm{O}\right)\right]^{2+}\left(\mathrm{Ru}_{\text {cat }}^{\mathrm{II}}-\mathrm{H}_{2} \mathrm{O}\right)$, where the percentage of $\mathbf{P 1}$ repeat units relative to $\left[\left[4^{\prime}\right.\right.$-phenyl-2,2':6',2"-terpyridine $] \mathrm{Ru}(\mathrm{bpy})$ $\left.\left(\mathrm{H}_{2} \mathrm{O}\right)\right]^{2+}(20: 1)$ was identical to the ratio of Ru chromophore to terminal units in P2 $(20: 1)$. The DPV scan for P1 features a typical $\mathrm{Ru}^{\mathrm{III}} / \mathrm{Ru}^{\mathrm{II}}$ oxidation at $1.27 \mathrm{~V}$ vs. NHE. The mixture of P1 and $\left[\left[4^{\prime} \text {-phenyl-2,2':6', 2"-terpyridine }\right] \mathrm{Ru}(\mathrm{bpy})\left(\mathrm{H}_{2} \mathrm{O}\right)\right]^{2+}$ exhi- bits a wave at $0.82 \mathrm{~V}$ vs. NHE for the $\mathrm{Ru}_{\text {cat }}^{\mathrm{III}}-\mathrm{H}_{2} \mathrm{O} / \mathrm{Ru}_{\text {cat }}^{\mathrm{II}}-\mathrm{H}_{2} \mathrm{O}$ redox couple and a barely discernible feature at $1.04 \mathrm{~V} v s$. NHE attributed to the PCET inhibited $\mathrm{Ru}_{\text {cat }}^{\mathrm{IV}}=\mathrm{O} / \mathrm{Ru}_{\text {cat }}^{\mathrm{III}}-\mathrm{H}_{2} \mathrm{O}$ couple. The $\mathrm{Ru}_{\text {cat }}^{\mathrm{IV}}=\mathrm{O} / \mathrm{Ru}_{\text {cat }}^{\mathrm{III}}-\mathrm{H}_{2} \mathrm{O}$ wave is kinetically distorted because of the proton-coupled electron transfer (PCET) nature of the half reaction arising from formation of $\mathrm{Ru}_{\mathrm{cat}}=\mathrm{O}^{14}$ in the propylene carbonate medium. For $\mathbf{P} 2$ only the $\mathrm{Ru}_{\text {cat }}^{\mathrm{III}}-\mathrm{H}_{2} \mathrm{O} / \mathrm{Ru}_{\text {cat }}{ }^{\mathrm{II}}$ $\mathrm{H}_{2} \mathrm{O}$ oxidation was observed, at $E_{1 / 2}=0.84 \mathrm{~V} v s$. NHE. As expected given the chromophore: catalyst ratio in the assembly, the peak current ratio for chromophore to catalyst was close to the $1: 20$ ratio expected given the composition of the assembly. ${ }^{15}$ Similar results were obtained for the polymer assembly on nano-ITO electrodes (see Fig. S4 in the ESI $\dagger$ ).

\section{Absorption and emission spectra}

In solution, UV-visible spectra of $\mathbf{P 1}$ and $\mathbf{P 2}$ share similar absorption features with a small contribution from $-\mathrm{Ru}_{\text {cat }}^{\text {II }}$ $\mathrm{OH}_{2}$ relative to the $\mathrm{Ru}(\mathrm{II})$ chromophores in P2, Fig. 2a. The metal-to-ligand charge transfer (MLCT) absorption manifolds 


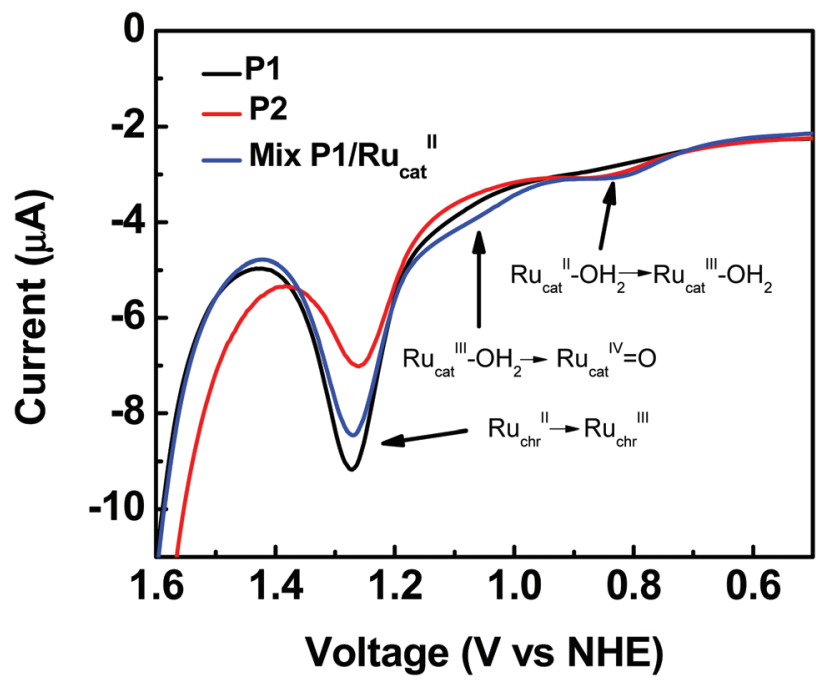

Fig. 1 Differential pulse voltammograms of $\mathbf{P 1}, \mathbf{P 2}$ and a $\mathrm{P} 1 / \mathrm{Ru}_{\text {cat }}^{\prime \prime}-\mathrm{H}_{2} \mathrm{O}$ ([[4'-phenyl-2,2':6',2"-terpyridine $\left.\mathrm{Ru}(\mathrm{bpy})\left(\mathrm{H}_{2} \mathrm{O}\right)\right]^{2+}$ ) mixture $(20: 1)$ in deaerated $0.1 \mathrm{M} \mathrm{Bu}_{4} \mathrm{NPF}_{6}$ propylene carbonate solution, scan rate: $50 \mathrm{mV} \mathrm{s}^{-1}$. maximize at $460 \mathrm{~nm}$, with $\pi-\pi^{*}$ bpy-based absorptions at $290 \mathrm{~nm}$. In the spectrum of $\mathbf{P 2}$ a slight redshift in the $\pi-\pi^{*}$ absorption is observed with a slight broadening for the MLCT manifold similar to the sum of the spectra of $\mathbf{P 1}$ and $\mathrm{Ru}_{\text {cat }}^{\mathrm{II}}-\mathrm{H}_{2} \mathrm{O}$. Similar observations were made in the emission spectra in Fig. $2 \mathrm{~b}$ with the observation of $\sim 15 \%$ emission quenching for P2 compared to P1. For the $\mathrm{Ru}_{\text {cat }}^{\mathrm{II}}-\mathrm{H}_{2} \mathrm{O}(1: 20)$ mixture with P1 control, less than $2 \%$ quenching occurs. The results are consistent with excitation and energy transfer migration within the polymer strand for $\mathbf{P 2}$ to the lower-lying $\mathrm{Ru}_{\text {cat }}^{\mathrm{II}}-\mathrm{H}_{2} \mathrm{O}$-based excited state which is a weak emitter with a short-lived excited state.

Emission spectra were analyzed by application of a single mode, Franck-Condon analysis as described previously. ${ }^{16}$ Observed and simulated spectra are shown in Fig. 2c. The spectra are broad and featureless, characteristic of MLCT spectra of $\mathrm{Ru}(\mathrm{II})$ polypyridyl complexes at room temperature. ${ }^{17}$

$$
I(\tilde{\nu})=\sum_{v_{\mathrm{M}}=0}^{\infty}\left(\frac{E_{0}-v_{\mathrm{M}} \hbar \omega_{\mathrm{M}}}{E_{0}}\right)^{3}\left(\frac{S_{\mathrm{M}}^{v_{\mathrm{M}}}}{v_{\mathrm{M}} !}\right) \exp \left[-4 \ln 2\left(\frac{\tilde{\nu}-E_{0}+v_{\mathrm{M}} \hbar \omega_{\mathrm{M}}}{\Delta \tilde{\nu}_{1 / 2}}\right)^{2}\right]
$$
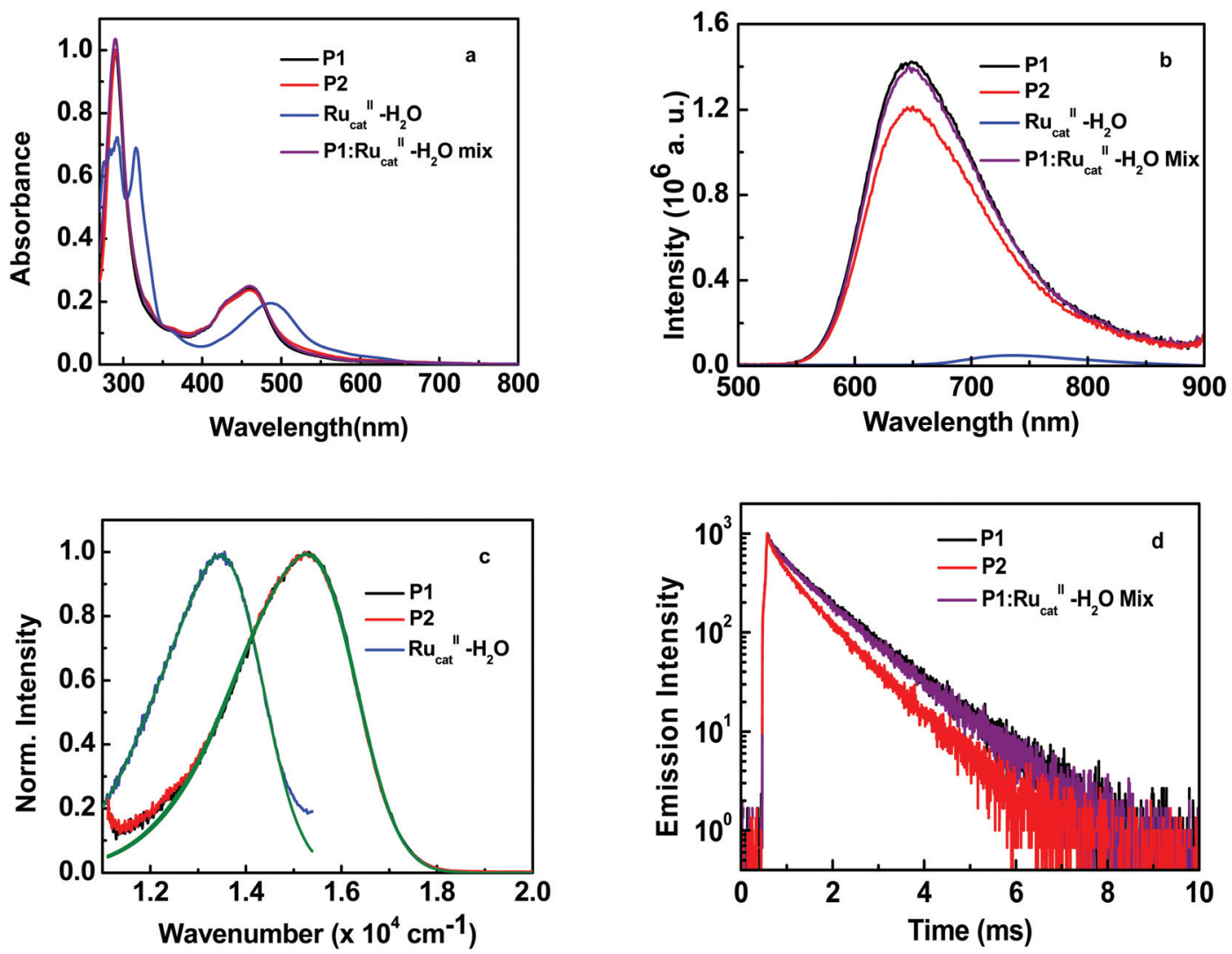

Fig. 2 (a) Absorption and (b) emission spectra of P1, P2, Ru cat $-\mathrm{H}_{2} \mathrm{O}$ ([[4'-phenyl-2,2':6',2"'-terpyridine $\left.\left.] \mathrm{Ru}(\mathrm{bpy})\left(\mathrm{H}_{2} \mathrm{O}\right)\right]^{2+}\right)$ and a mixture of P1 with $\mathrm{Ru}_{\mathrm{cat}}^{\mathrm{II}}-\mathrm{H}_{2} \mathrm{O}$, (c) wavenumber-scale emission spectra of $\mathrm{P} 1, \mathrm{P} 2$ and $\mathrm{Ru}_{\mathrm{cat}}^{\prime \prime}-\mathrm{H}_{2} \mathrm{O}$ at $298 \mathrm{~K}$ with simulated spectra (olive curves) obtained by single-mode Franck-Condon analysis of emission spectra (eqn (1)) with the fitting parameters listed in Table 1, and (d) emission decay profiles for P1, P2 and the mixture of $\mathrm{P} 1$ and $\mathrm{Ru}_{\text {cat }}^{\prime \prime}-\mathrm{H}_{2} \mathrm{O}$ in DMF at $298 \mathrm{~K}$ monitored at $650 \mathrm{~nm}$. Ru(II) concentration, $10 \mu \mathrm{M}$; ratio of Ru(II) in $\mathrm{P} 1$ to $\mathrm{Ru}$ cat $-\mathrm{H}_{2} \mathrm{O}$ in the mixed sample was $20: 1$; excitation wavelength, $445 \mathrm{~nm}$. 
Table 1 Spectral fitting parameters derived from analysis of emission spectra for $\mathbf{P 1}, \mathbf{P 2}$, and $\mathrm{Ru}_{\text {cat }}^{\prime \prime}-\mathrm{H}_{2} \mathrm{O}$ at $298 \mathrm{~K}$ in DMF

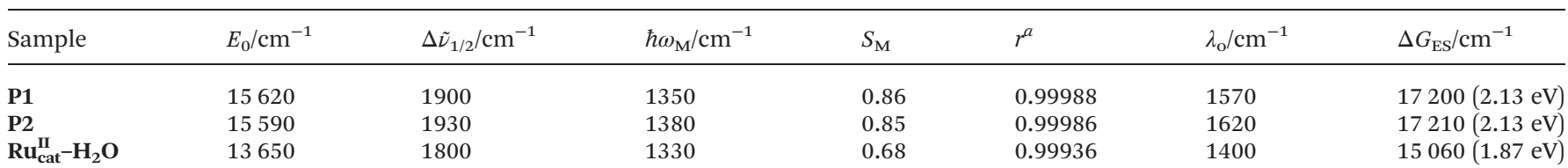

${ }^{a}$ Correlation coefficient.

In eqn (1), $I(\tilde{\nu})$ is the emission intensity at the energy $\tilde{\nu}$ in wavenumbers $\left(\mathrm{cm}^{-1}\right)$, relative to the intensity of the $0 \rightarrow 0$ transition. $E_{0}$ is the energy gap between the zero vibrational levels of the ground and excited states. $v_{\mathrm{M}}, \hbar \omega_{\mathrm{M}}$ and $S_{\mathrm{M}}$ are the vibrational quantum number, the quantum spacing and the Huang-Rhys factor reflecting the degree of distortion in the single, average mode as the difference in equilibrium displacements, respectively. $\Delta \tilde{\nu}_{1 / 2}$ is the full width at half-maximum (fwhm) for individual vibronic lines. Emission intensities, corrected to wavenumbers by $I(\tilde{\nu})=[I(\lambda)] \lambda^{2}$, were fit by optimizing the parameters $E_{0}, \Delta \tilde{\nu}_{1 / 2}, \hbar \omega_{\mathrm{M}}$, and $S_{\mathrm{M}}$ with a least squares minimization routine which utilizes a generalized reduced gradient (GRG2) algorithm. ${ }^{18}$ The summation was carried out over 11 ground-state vibrational levels $\left(v_{M}=0 \rightarrow 10\right)$. The free energy content of the polymer-based excited state above the ground state, $\Delta G_{\mathrm{ES}}$, was calculated by eqn (2) with values presented in Table 1.

$$
\Delta G_{\mathrm{ES}}=E_{0}+\frac{\left(\Delta \tilde{\nu}_{1 / 2}\right)^{2}}{16 k_{\mathrm{B}} T \ln 2}
$$

Table 1 summarizes spectral fitting results for both polymers and catalyst $\mathrm{Ru}_{\text {cat }}^{\mathrm{II}}-\mathrm{H}_{2} \mathrm{O}$. The catalyst emits at lower energy and is short-lived compared to the chromophore sites in P1. The decrease in lifetime for $\mathbf{P 2}$ is consistent with intrastrand energy transfer to the catalyst by site-to-site hopping followed by energy transfer to the catalyst and its rapid decay. In eqn (2), $k_{\mathrm{B}}$ and $T$ are the Boltzmann constant and absolute temperature, respectively. The free energy change for energy transfer from chromophore excited state to catalyst, $\Delta G_{\text {en }}$, was calculated by eqn (3) with (acceptor) the catalyst energy acceptor and (donor) the excited polymer chromophore.

$$
\Delta G_{\mathrm{en}}=\Delta G_{\mathrm{ES}}(\text { acceptor })-\Delta G_{\mathrm{ES}}(\text { donor })
$$

Based on the values in Table 1, the free energy change for $-\mathrm{Ru}^{\mathrm{II} *}$ - to $\mathrm{Ru}_{\text {cat }}^{\mathrm{II}}-\mathrm{H}_{2} \mathrm{O}$ energy transfer is favorable with $\Delta G_{\text {en }} \sim$ $-2100 \mathrm{~cm}^{-1}(-0.26 \mathrm{eV})$ showing that emission quenching in $\mathbf{P} 2$ relative to $\mathbf{P 1}$ is consistent with intrastrand energy transfer to the terminal catalyst site.

\section{Emission decay}

Emission decays were obtained by time-correlated single photon counting (TCSPC) with the results illustrated in Fig. 2d. All emission decays were multiple exponential consistent with heterogeneity and a distribution of emitting sites along the polymer chain. Both P1 ( $\sim 840 \mathrm{~ns})$ and the sample mixture ( $\sim 800$ ns) have comparable average lifetimes with the lifetime of P2 decreased to $\sim 640$ ns consistent with partial intra-strand quenching.

\section{Excited-state quenching}

The dynamics of excited state electron transfer quenching with added electron-transfer quencher methylviologen dication $\left(\mathrm{MV}^{2+}\right)$ were investigated by time-resolved fluorescence and transient absorption measurements in DMF at room temperature. In these experiments, the concentration of $\mathrm{MV}^{2+}$ was varied from 0-20 mM.

Fig. 3a and $\mathrm{b}$ show emission spectra and emission decay profiles for $\mathbf{P} 2$ in the absence and presence of $\mathrm{MV}^{2+}$. With the addition of $\mathrm{MV}^{2+}$, both rapid and slow quenching components are observed (Fig. 3b). The rapid component is due to preassociation of the quencher with $\mathrm{Ru}(\mathrm{II})$ sites along the polymer chains. ${ }^{19}$ Absorption or emission-time dynamics for the slow component are bi-exponential. Fig. 3c shows Stern-Volmer plots for $\mathbf{P} 2$ quenching by both quenching pathways. The slow data follow Stern-Volmer kinetics with, $\tau_{0} / \tau=1+k_{\mathrm{q}, \text { diff }}$ $\tau_{0}\left[\mathrm{MV}^{2+}\right]$. In this expression, $\tau_{0}$ is the emission lifetime of $\mathbf{P 2}$ ( $\sim 800 \mathrm{~ns})$ in the absence of $\mathrm{MV}^{2+}$, and $\tau$ in the presence of $\mathrm{MV}^{2+} . k_{\mathrm{q}, \mathrm{diff}}$ is the rate constant for the diffusional quenching component with $k_{\mathrm{q} \text {,diff }} \sim 2.0 \times 10^{7} \mathrm{M}^{-1} \mathrm{~s}^{-1}$ from the slope of the Stern-Volmer plot.

The kinetics for the rapid quenching component are complicated by overlapping contributions from pre-associated quencher and slower diffusional quenching. Emission quenching data were treated by use of the expression, $\phi_{0} / \phi=\left(1+K_{\mathrm{s}}\right.$ $\left.\left[\mathrm{MV}^{2+}\right]\right)\left(1+k_{\mathrm{q}, \mathrm{diff}} \tau_{0}\left[\mathrm{MV}^{2+}\right]\right)=1+\left(k_{\mathrm{q}, \text { diff }}+k_{\mathrm{q}}\right) \tau_{0}\left[\mathrm{MV}^{2+}\right]+k_{\mathrm{q}} k_{\mathrm{q}, \mathrm{diff}}$ $\tau_{0}^{2}\left[\mathrm{MV}^{2+}\right]^{2}$. In this expression, $K_{\mathrm{s}}$ is the association constant between quencher and polymer and $k_{\mathrm{q}}$ is the quenching rate constant for the pre-associated quencher-polymer complex. Based on the data for the rapid and slow quenching components in Fig. $3 \mathrm{c}, k_{\mathrm{q}} \sim 1.04 \times 10^{8} \mathrm{M}^{-1} \mathrm{~s}^{-1}$.

In transient absorption spectra, addition of $\mathrm{MV}^{2+}$ and excited-state quenching of $-\mathrm{Ru}^{\mathrm{II}}{ }^{*}$ - by oxidative electron transfer gives rise to new absorption features at 396 and $607 \mathrm{~nm},{ }^{20,21}$ Fig. 4 and S6. $\dagger$ These features are characteristic of the reduced radical cation, $\mathrm{MV}^{++}$, formed in the reaction, $-\mathrm{Ru}^{\mathrm{II} *_{-}}+\mathrm{MV}^{2+} \rightarrow-\mathrm{Ru}^{\mathrm{III}}-+\mathrm{MV}^{+}$. The formal potential for the $-\mathrm{Ru}^{\mathrm{III}}-/-\mathrm{Ru}^{\mathrm{II}^{*}}{ }_{-}$couple is $E_{\mathrm{ox}}\left(\mathrm{III} / \mathrm{II}^{*}\right)=-0.86 \mathrm{~V} v s$. NHE as calculated from, $E_{\mathrm{ox}}\left(\mathrm{III} / \mathrm{III}^{*}\right)=E(\mathrm{III} / \mathrm{II})-\Delta G_{\mathrm{ES}} / n F$. In this relationship $F$ is the Faraday constant in eV per equivalent, with $E(\mathrm{III} / \mathrm{II})=1.27$ $\mathrm{V} v s$. NHE from the electrochemical measurements and $\Delta G_{\mathrm{ES}}=$ $17200 \mathrm{~cm}^{-1}(2.13 \mathrm{eV})$ from emission spectral fitting. With $E$ 

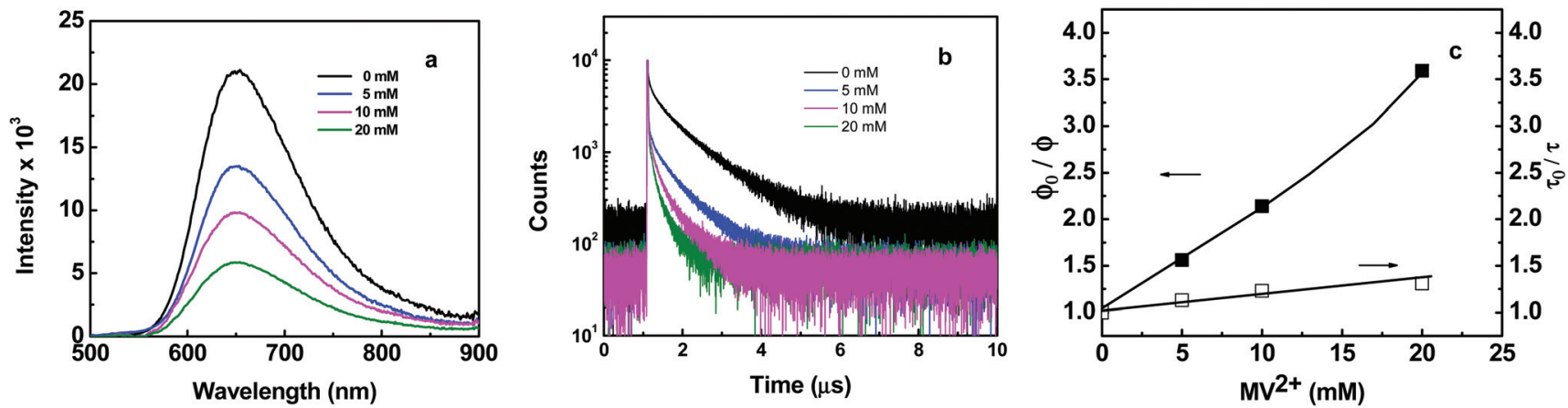

Fig. 3 Emission spectra (a) and decay profiles (b) for P2 in the absence and presence of $\mathrm{MV}^{2+}$. Stern-Volmer plots (c) for P2 quenched by preassociation (closed squares) and by diffusional quenching (open squares) by $\mathrm{MV}^{2+}$. The concentration of Ru(II) sites in the DMF solutions was $10 \mu \mathrm{M}$ with $\left[\mathrm{MV}^{2+}\right]=0,5,10$, and $20 \mathrm{mM}$. The excitation wavelength was $445 \mathrm{~nm}$.
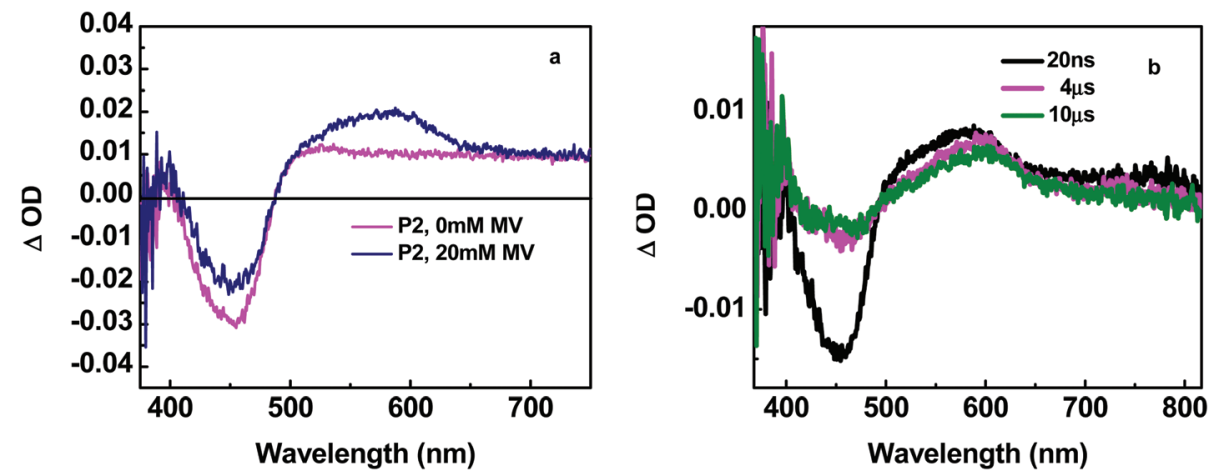

Fig. 4 (a) Transient absorption difference spectra for P2 with and without added $\mathrm{MV}^{2+}$ in deaerated DMF obtained $\sim 20 \mathrm{~ns}$ after $425 \mathrm{~nm}$ laser flash excitation, and (b) the spectra at different times following excitation. Ruthenium site concentration, $20 \mu \mathrm{M}$.

$\left(\mathrm{MV}^{2+} / \mathrm{MV}^{*+}\right)=-0.45 \mathrm{~V}$ vs. $\mathrm{NHE}{ }^{22}$ the oxidation of $-\mathrm{Ru}^{\mathrm{II}}$ - by $\mathrm{MV}^{2+}$ is thermodynamically favored with $\Delta G^{\mathrm{O}^{\prime}}=\sim 0.4 \mathrm{eV}$.

As shown in Fig. 4, the transient absorption difference spectrum for $\mathbf{P 2}$, following $425 \mathrm{~nm}$ laser flash excitation, obtained at $20 \mathrm{~ns}$ after the laser flash, exhibits features similar to those for P1 (Fig. S5a in the ESI $\dagger$ ). In these spectra, a $\pi-\pi^{*}$ absorption feature for a reduced ligand appears at $\sim 390 \mathrm{~nm}$ and a bleach for the loss of the MLCT absorption feature at $\sim 460 \mathrm{~nm}^{23}$ Both emission decays at $630 \mathrm{~nm}$ for $\mathbf{P 1}$ and $\mathbf{P 2}$ in the absence of $\mathrm{MV}^{2+}$ were non-exponential but could be fit to multi-exponential kinetics with contributions to the complexity from excited state intra-strand energy transfer hopping and inhomogenities at the individual sites in the polymers. ${ }^{8,9}$ Note the quenching and back electron transfer scheme in Fig. 6. The data were fit to a biexponential function with a rapid decay component with $\tau=20-30$ ns and a slower decay component with $\tau \sim 1 \mu \mathrm{s}$. The kinetics of loss of the bleach at $460 \mathrm{~nm}$ for both polymers exhibited kinetics that mirrored the $630 \mathrm{~nm}$ emission decay (Fig. 5).

A contribution to the slow, $10 \mu \mathrm{s}$, growth at $460 \mathrm{~nm}$ appears due to relatively slow back electron transfer from $\mathrm{MV}^{*+}$ to $\mathrm{Ru}(\mathrm{III})$ (Fig. 4 and S5 in ESI, $\uparrow$ which occurs in concert with the decrease in absorbance by $\mathrm{MV}^{+}$at $600 \mathrm{~nm}$. Following excitation, the excited chromophore, $-\mathrm{Ru}^{\mathrm{II}_{*}}$, is oxidized by pre-associated or diffusional $\mathrm{MV}^{2+}$. Following oxidation, $-\mathrm{Ru}^{\mathrm{III}}$ - undergoes electron transfer with adjacent sites along the polymer chain resulting in net hole migration. Intra-strand migration eventually reaches the low potential catalyst site at the terminus, $-\mathrm{Ru}_{\text {cat }}^{\mathrm{III}}$, on the $\sim \mathrm{ns}$ time range in competition with back electron transfer with $\mathrm{MV}^{*+}$, Fig. 6 .

Back electron transfer from $\mathrm{MV}^{*+}$ to either $-\mathrm{Ru}_{\text {cat }}^{\text {III }}$ or $-\mathrm{Ru}_{\text {chr }}^{\text {III }}$ is highly favorable given the $1.27 \mathrm{~V} v$ s. NHE potential for the $-\mathrm{Ru}^{\mathrm{II} / \mathrm{II}}$ - couple. Back electron transfer kinetics were studied by analyzing absorbance-time traces for loss of $\mathrm{MV}^{*+}$ at $600 \mathrm{~nm}$. As shown in Fig. S7, $\dagger$ the data could be fit to equal concentration, second order kinetics consistent with the reaction, $\mathrm{MV}^{++}+\mathrm{Ru}(\mathrm{III}) \rightarrow \mathrm{MV}^{2+}+\mathrm{Ru}(\mathrm{II})$, according to the expression, $\frac{1}{\left[\mathrm{MV}^{{ }^{+}}\right]}-\frac{1}{\left[\mathrm{MV}^{\bullet^{+}}\right] 0}=k t$, with $\left[\mathrm{MV}^{\bullet+}\right]=$ $\Delta \mathrm{OD} / \varepsilon l .\left[\mathrm{MV}^{\circ+}\right]_{\mathrm{o}}, \varepsilon, l$ and $\Delta \mathrm{OD}$ are the initial concentration of $\mathrm{MV}^{\cdot+}$, the molar extinction coefficient for $\mathrm{MV}^{\circ+}$ ( 13 $\left.800 \mathrm{M}^{-1} \mathrm{~cm}^{-1}\right), l$, the light path, was $1 \mathrm{~cm}$, and $\Delta O D$ the optical density change. ${ }^{13}$ Back electron-transfer rate constants obtained from the data for the reactions between $\mathrm{MV}^{\circ+}$ and $\mathrm{Ru}(\mathrm{III})$ in $\mathbf{P 1}$ and $\mathbf{P 2}$ were $7.6 \times 10^{9}$, and $8.2 \times 10^{9} \mathrm{M}^{-1} \mathrm{~s}^{-1}$, respectively. 

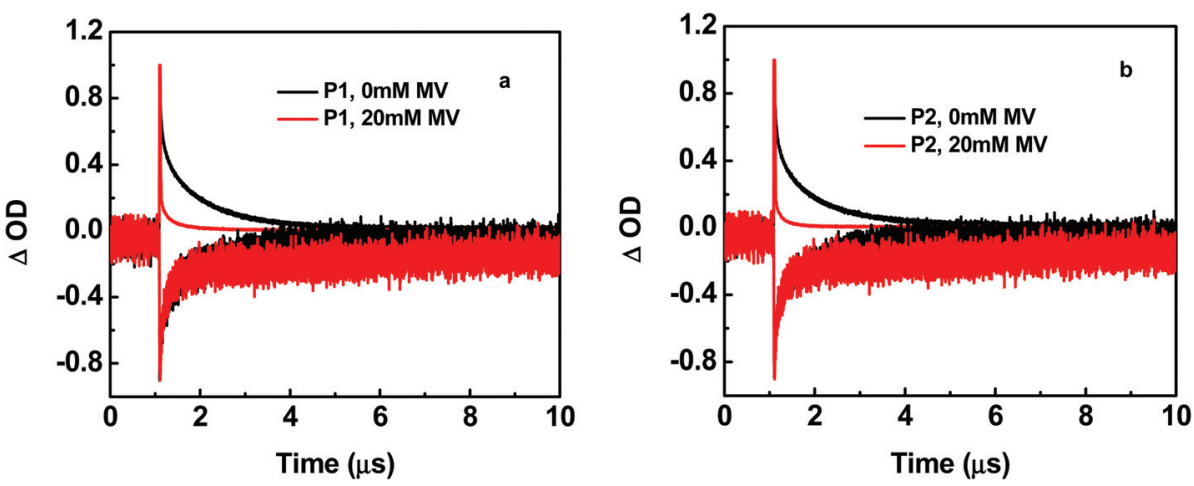

Fig. 5 Absorbance bleach at $460 \mathrm{~nm}$ and emission decay at $630 \mathrm{~nm}$ for P1 (a) and P2 (b) with and without MV ${ }^{2+}$ (20 mM), following $425 \mathrm{~nm}$ excitation in degassed DMF. Ru(II) site concentration, $20 \mu \mathrm{M}$. The absorbance-traces for slow recovery of the bleach feature at $460 \mathrm{~nm}$ are consistent with slow back electron transfer from $\mathrm{MV}^{++}$to $\mathrm{Ru}(\mathrm{III})$ with added $\mathrm{MV}^{2+}$.

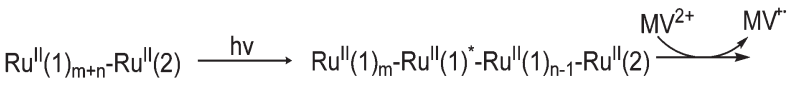

$$
\begin{aligned}
& R u^{\prime \prime}(1)_{m}-R u^{\prime \prime \prime}(1)-R u^{\prime \prime}(1)_{n-1}-R u^{\prime \prime}(2) \stackrel{e^{-} \text {hopping }}{\longrightarrow} R u^{\prime \prime}(1)_{m}-R u^{\prime \prime}(1)-R u^{\prime \prime \prime}(1)_{n-1}-R u^{\prime \prime}(2) \\
& \text { back e transfer } \\
& \operatorname{Ru}^{\prime \prime}(1)_{m+n}-\mathrm{Ru}^{\prime \prime}(2) \\
& \operatorname{Ru}^{\prime \prime}(1)_{m+n}-e^{-} \text {transfer }
\end{aligned}
$$

Fig. 6 Excitation, energy transfer migration, excited state electron transfer, and electron transfer migration in solutions containing $\mathrm{MV}^{2+}$ and P2 in DMF. The labels 1 and 2 are for the chromophore and catalyst sites, respectively.

Transient absorption and electrochemical measurements on oxide surfaces

Given the ultimate interest in utilizing molecular assemblies in DSPEC applications, the photophysical and electrochemical properties of polymers on the surfaces of nanoparticle, mesoscopic metal oxide films of $\mathrm{ZrO}_{2}, \mathrm{TiO}_{2}$ and ITO were also investigated. Nano- $\mathrm{TiO}_{2}$ films and nano- $\mathrm{ZrO}_{2}$ films, typically $6 \mu \mathrm{m}$ thick, coating an area, $11 \mathrm{~mm} \times 11 \mathrm{~mm}$, on FTO (fluorinedoped $\mathrm{SnO}_{2}$ ) glass, were prepared according to previously published procedures. ${ }^{24}$ Chromophore adsorption in the nanoparticle films was carried out by immersing the resulting slides in $0.2 \mathrm{mM}$ solutions of the polymers in DMF solutions, followed by soaking an additional $4 \mathrm{~h}$ in pure DMF solvent to remove any aggregates/free polymers in the film. The slides were removed, rinsed with methanol, and dried under a stream of nitrogen. Surface coverages $\left(\Gamma\right.$ in $\left.\mathrm{mol} \mathrm{cm}^{-2}\right)$ were estimated by UV-visible measurements by using the expression $\Gamma=A(\lambda) / \varepsilon(\lambda) / 1000$, with solution molar extinct coefficients $(\varepsilon)$ used in the calculations. ${ }^{25} A(\lambda)$ was the maximum absorbance of the derivatized slides.

Due to the large molecular size of the polymer assemblies, with $\sim 20$ repeat units and molecular weights over $20 \mathrm{~K}$, and only a single anchoring group at the end, low surface coverages $\left(10^{-10}-10^{-9} \mathrm{~mol} \mathrm{~cm}^{-2}\right.$ in $\mathrm{Ru}(\mathrm{II})$ polypyridyl sites) were obtained on both nanoZrO ${ }_{2}$, and nanoTiO . The limited surface coverages suggest that surface binding may be limited, in part due to the limited internal volume of the voids in the oxide films given the large molecular volumes of the polymers. We recently reported that within the $\mathrm{TiO}_{2}$ nanoparticle pores $(\sim 20 \mathrm{~nm})$, the maximum number of $\mathrm{Ru}(\mathrm{II})$ polypyridyl complexes that could be grown from a surface-bound precursor was seven. ${ }^{26}$ The polymer-catalyst assemblies reported here with $\sim 20 \mathrm{Ru}$ (II) bpy units is too large to enter the cavities in the films resulting in low coverages. The polymer presumably occupies channels and the surfaces of the oxide films.

For $\mathbf{P} 2$ compared to $\mathbf{P 1}$ on $\mathrm{ZrO}_{2}$ nanoparticle films, partial quenching was observed with propylene carbonate as the external solvent, Fig. S8. $\dagger$ The conduction band potential for $\mathrm{ZrO}_{2}$ at $-1.4 \mathrm{~V} v s$. NHE at $\mathrm{pH} 7$ in water, is inaccessible for injection by the polymer-based $-\mathrm{Ru}^{\mathrm{II} *}$ - excited state with $E_{\text {ox }}\left(\mathrm{III} / \mathrm{II}^{*}\right)=$ $-0.86 \mathrm{~V}^{27}$ The decreased emission intensity for $\mathbf{P} 2$ relative to $\mathbf{P 1}$, as in solution, is presumably due to intra-strand energy transfer migration to the terminal catalyst site which acts as an energy transfer trap.

With $\mathrm{TiO}_{2}$ as the substrate, substantial emission quenching was observed for both $\mathbf{P 1}$ and $\mathbf{P 2}$, due to the excited state electron injection into $\mathrm{TiO}_{2}$. Injection efficiencies for both polymers on $\mathrm{TiO}_{2}$ are comparable, $\sim 50 \%$ as estimated from the decrease in emission intensities, Fig. S8. $\dagger$

Electrocatalytic water oxidation by $\mathbf{P} 2$ was investigated on $\sim 6 \mu \mathrm{m}$ nanoparticle, mesoscopic films of nanoITO. As estimated by UV-visible measurements, the surface coverage was $\sim 1.6 \times 10^{-10} \mathrm{~mol} \mathrm{~cm}^{-2}$. The derivatized oxide was used as the working electrode in a three compartment electrochemical cell with a Pt wire as the counter electrode and $\mathrm{AgNO}_{3} / \mathrm{Ag}$ as the reference in propylene carbonate $0.1 \mathrm{M}$ in $\mathrm{Bu}_{4} \mathrm{NPF}_{6}$. Cyclic voltammograms are shown in Fig. 7 relative to the un-derivatized electrode as a background.

With increasing amounts of added water, from $0 \%$ to $8 \%$ by volume, the $\mathrm{Ru}(\mathrm{III}) / \mathrm{Ru}$ (II) couple shifts from $1.29 \mathrm{~V}$ to $1.20 \mathrm{~V}$ due to a selective outer sphere solvation effect. A noticeable increase in current at $\sim 1.8 \mathrm{~V}$ with successive additions of water 


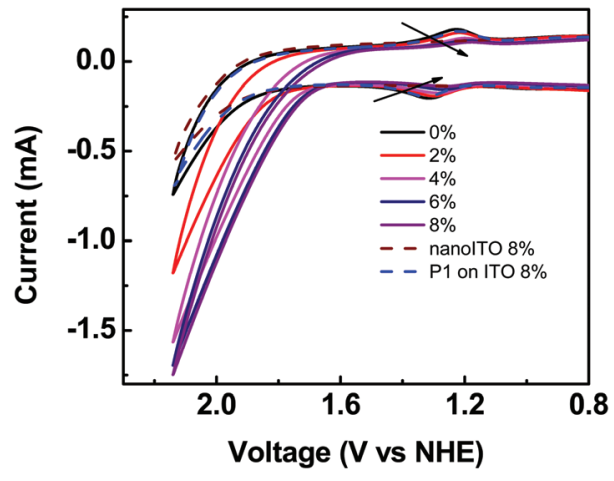

Fig. 7 Cyclic voltammograms of P2 on nanolTO, in propylene carbonate $0 \%, 2 \%, 4 \%, 6 \%$, and $8 \%$ added water by volume. Scan rate, $50 \mathrm{mV}$ $\mathrm{s}^{-1} ; 0.1 \mathrm{M} \mathrm{Bu}_{4} \mathrm{NPF}_{6}$ as the supporting electrolyte. The nanolTO electrode area is $\sim 1 \mathrm{~cm}^{2}$

also appears in the voltammograms. The enhanced current for the assembly-derivatized electrode relative to ITO and P1/ITO is notable and consistent with water oxidation catalysis by the terminal single site catalyst ${ }^{28}$ Possible photochemically driven water oxidation catalysis is currently under investigation.

\section{Conclusions}

We have described here the preparation and properties of a $\mathrm{Ru}(\mathrm{II})$ polypyridyl-derivatized polypropylacrylate polymer with a water oxidation catalyst at the terminus. The polymer was synthesized by RAFT polymerization followed by click reaction coupling to the polymer backbone and then end-group functionalization. In the final chromophore-catalyst assembly polymer, the chromophore: catalyst ratio was $20: 1$. The redox properties of the terminal catalyst are observed in both cyclic and differential pulse voltammograms. Upon excitation of the chromophore-catalyst polymer there is evidence for excitation of the chromophore on the polymer backbone followed by energy transfer migration and quenching by energy transfer to the catalyst which is favored by $\Delta G_{\mathrm{en}}=-2100 \mathrm{~cm}^{-1}(-0.26 \mathrm{eV})$. With added $\mathrm{MV}^{2+}$, electron transfer quenching of the MLCT excited states of the $\mathrm{Ru}(\mathrm{II})$ chromophores on the polymer occurs, as shown by transient absorption measurements and the appearance of $\mathrm{MV}^{++}$. Electron transfer quenching is followed by site-to-site hole migration along the polymer chain to the terminal catalyst site in competition with back electron transfer from $\mathrm{MV}^{*+}$.

Electron transfer and excited state properties are retained by surface binding of the catalyst-derivatized polymer on the surfaces of nanoparticle, mesoscopic oxide electrodes as shown by electrochemical and transient spectroscopic measurements. The polymer chromophore-terminal catalyst assembly is important in demonstrating a new chromophorequencher design. It introduces multiple light absorbers in a polymeric framework for enhanced light harvesting with a terminal water oxidation catalyst. The polymer is end-group derivatized for surface binding to oxide substrates.

Future work will focus on improvement of assembly design to enhance surface loading and possible applications in DSPEC devices for water splitting. In the next generation of polymer assembly, more efficient water oxidation catalysts based on carbene and Mebimpy ligands ${ }^{28,29}$ will be introduced.

\section{Acknowledgements}

This material is based upon work solely supported as part of the UNC EFRC: Center for Solar Fuels, an Energy Frontier Research Center funded by the U.S. Department of Energy, Office of Science, Office of Basic Energy Science under Award Number DE-SC0001011.

\section{Notes and references}

1 (a) W. J. Youngblood, S.-H. Lee, Y. Kobayashi, E. A. Hernandez-Pagan, P. G. Hoertz, T. A. Moore, A. L. Moore, D. Gust and T. E. Mallouk, J. Am. Chem. Soc., 2009, 131, 926; (b) D. Gust, T. A. Moore and A. L. Moore, Acc. Chem. Res., 2009, 42, 1890; (c) L. Sun, L. Hammarstrom, B. Akermark and S. Styring, Chem. Soc. Rev., 2001, 30, 36; (d) W. Song, Z. Chen, M. K. Brennaman, J. Concepcion and T. J. Meyer, Pure Appl. Chem., 2011, 83, 749; (e) B. Zhang, F. Li, F. Yu, X. Wang, X. Zhou, H. Li, Y. Jiang and L. Sun, ACS Catal., 2014, 4, 804.

2 (a) W. J. Youngblood, S.-H. Lee, K. Maeda and T. E. Mallouk, Acc. Chem. Res., 2009, 42, 1966; (b) M. Yagi and M. Kaneko, Chem. Rev., 2001, 101, 21; (c) Y. Zhao, J. R. Swierk, J. D. Megiatto Jr., B. Sherman, W. J. Youngblood, D. Qin, D. M. Lentz, A. L. Moore, T. A. Moore, D. Gust and T. E. Mallouk, Proc. Natl. Acad. Sci. U. S. A., 2012, 109, 15612; (d) L. Alibabaei, H. Luo, R. L. House, P. G. Hoertz, R. Lopez and T. J. Meyer, J. Mater. Chem. A, 2013, 1, 4133.

3 (a) T. Meyer, J. Papanikolas and C. Heyer, Catal. Lett., 2011, 141, 1; (b) L. Alibabaei, M. K. Brennaman, M. R. Norris, B. Kalanyan, W. Song, M. D. Losego, J. J. Concepcion, R. A. Binstead, G. N. Parsons and T. J. Meyer, Proc. Natl. Acad. Sci. U. S. A., 2013, 110, 20008; (c) W. R. McNamara, R. L. Milot, H. Song, R. C. Snoeberger III, V. S. Batista, C. A. Schmuttenmaer, G. W. Brudvig and R. H. Crabtree, Energy Environ. Sci., 2010, 3, 917.

4 (a) C. Herrero, A. Quaranta, R.-A. Fallahpour, W. Leibl and A. Aukauloo, J. Phys. Chem. C, 2013, 117, 9605-9612; (b) J. A. Stull, R. D. Britt, J. L. McHale, F. J. Knorr, S. V. Lymar and J. K. Hurst, J. Am. Chem. Soc., 2012, 134, 19973; (c) J. A. Treadway, J. A. Moss and T. J. Meyer, Inorg. Chem., 1999, 38, 4386.

5 D. L. Ashford, W. Song, J. J. Concepcion, C. R. K. Glasson, M. K. Brennaman, M. R. Norris, Z. Fang, J. L. Templeton and T. J. Meyer, J. Am. Chem. Soc., 2012, 134, 19189. 
6 W. Song, C. R. K. Glasson, H. Luo, K. Hanson, M. K. Brennaman, J. J. Concepcion and T. J. Meyer, J. Phys. Chem. Lett., 2011, 2, 1808-1813.

7 M. R. Norris, J. J. Concepcion, D. P. Harrison, R. A. Binstead, D. L. Ashford, Z. Fang, J. L. Templeton and T. J. Meyer, J. Am. Chem. Soc., 2013, 135, 2080.

8 Y. Tamaki, T. Morimoto, K. Koike and O. Ishitani, Proc. Natl. Acad. Sci. U. S. A., 2012, 109, 15678.

9 Y. Sun, Z. Chen, E. Puodziukynaite, D. M. Jenkins, J. R. Reynolds and K. S. Schanze, Macromolecules, 2012, 45, 2632.

10 (a) L. M. Dupray, M. Devenney, D. R. Striplin and T. J. Meyer, J. Am. Chem. Soc., 1997, 119, 10243; (b) C. N. Fleming, K. A. Maxwell, J. M. DeSimone, T. J. Meyer and J. M. Papanikolas, J. Am. Chem. Soc., 2001, 123, 10336.

11 M. K. Brennaman, A. O. T. Patrocinio, W. Song, J. W. Jurss, J. J. Concepcion, P. G. Hoertz, M. C. Traub, N. Y. Murakami Iha and T. J. Meyer, ChemSusChem, 2011, 4, 216.

12 Z. Liu, J. Hu, J. Sun and G. Liu, J. Polym. Sci., Part A: Polym. Chem., 2010, 48, 4922.

13 D. L. Ashford, D. J. Stewart, C. R. Glasson, R. A. Binstead, D. P. Harrison, M. R. Norris, J. J. Concepcion, Z. Fang, J. L. Templeton and T. J. Meyer, Inorg. Chem., 2012, 51, 6428.

14 V. Y. Shafirovich, S. H. Courtney, N. Q. Ya and N. E. Geacintov, J. Am. Chem. Soc., 1995, 117, 4920.

15 Z. Chen, J. J. Concepcion, H. Luo, J. F. Hull, A. Paul and T. J. Meyer, J. Am. Chem. Soc., 2010, 132, 17670.
16 Z. Murtaza, D. K. Graff, A. P. Zipp, L. A. Worl, W. E. Jones, W. D. Bates and T. J. Meyer, J. Phys. Chem., 1994, 98, 10504.

17 A. Ito and T. J. Meyer, Phys. Chem. Chem. Phys., 2012, 14, 13731.

18 D. Fylstra, L. Lasdon, J. Watson and A. Waren, Interfaces, 1998, 28, 29.

19 A. Ito, D. J. Stewart, Z. Fang, M. K. Brennaman and T. J. Meyer, Proc. Natl. Acad. Sci. U. S. A., 2012, 109, 15132.

20 T. Watanabe and K. Honda, J. Phys. Chem., 1982, 86, 2617.

21 J. F. Stargardt and F. M. Hawkridge, Anal. Chim. Acta, 1983, 146, 1.

22 P. Wardman, J. Phys. Chem. Ref. Data, 1989, 18, 1637.

23 J. H. Alstrum-Acevedo, M. K. Brennaman and T. J. Meyer, Inorg. Chem., 2005, 44, 6802.

24 S. Ito, T. N. Murakami, P. Comte, P. Liska, C. Grätzel, M. K. Nazeeruddin and M. Grätzel, Thin Solid Films, 2008, 516, 4613.

25 L. A. Gallagher, S. A. Serron, X. Wen, B. J. Hornstein, D. M. Dattelbaum, J. R. Schoonover and T. J. Meyer, Inorg. Chem., 2005, 44, 2089.

26 Z. Fang, S. Keinan, L. Alibabaei, H. Luo, A. Ito and T. J. Meyer, Angew. Chem., Int. Ed., 2014, 53, 4872.

27 R. Katoh, A. Furube, T. Yoshihara, K. Hara, G. Fujihashi, S. Takano, S. Murata, H. Arakawa and M. Tachiya, J. Phys. Chem. B, 2004, 108, 4818.

28 Z. Chen, J. J. Concepcion, H. Luo, J. F. Hull, A. Paul and T. J. Meyer, J. Am. Chem. Soc., 2010, 132, 17670.

29 M. R. Norris, J. J. Concepcion, Z. Fang, J. Templeton and T. J. Meyer, Angew. Chem., Int. Ed., 2013, 52, 13580. 